Supporting Information

\title{
Autonomous Shrinking/Swelling Phenomenon driven by Macromolecular Interchain Cross-linking via $\beta$-Cyclodextrin-Triazole Complexation
}

Yuuki Sugawara, ${ }^{\dagger}$ Toshiki Takei, ${ }^{\dagger}$ Hidenori Ohashi, ${ }^{\dagger \S}$ Hidenori Kuroki, ${ }^{\dagger \dagger}$ Shoji Miyanishi ${ }^{\dagger}$ and Takeo Yamaguchi ${ }^{*} \dagger$

${ }^{\dagger}$ Laboratory for Chemistry and Life Science, Institute of Innovative Research, Tokyo Institute of Technology, R1-17, 4259 Nagatsuta-cho, Midori-ku, Yokohama 226-8503, Japan

${ }^{\ddagger}$ Kanagawa Institute of Industrial Science and Technology (KISTEC), R1-17, 4259 Nagatsuta-cho, Midori-ku, Yokohama 226-8503, Japan

$\S$ (present address) Department of Chemical Engineering, Tokyo University of Agriculture and Technology (TUAT), 2-24-16 Naka-cho, Koganei, Tokyo 184-8588, Japan

*Corresponding author. E-mail: yamag@res.titech.ac.jp

\section{Contents:}

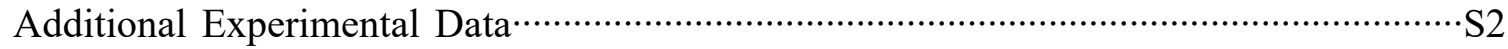

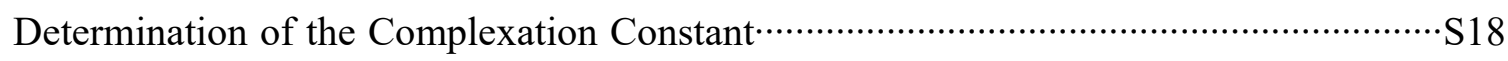

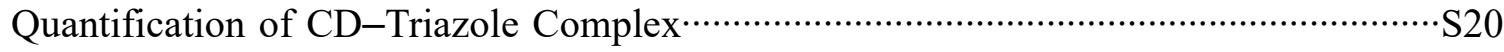

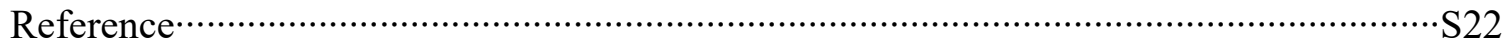




\section{Additional Experimental data}
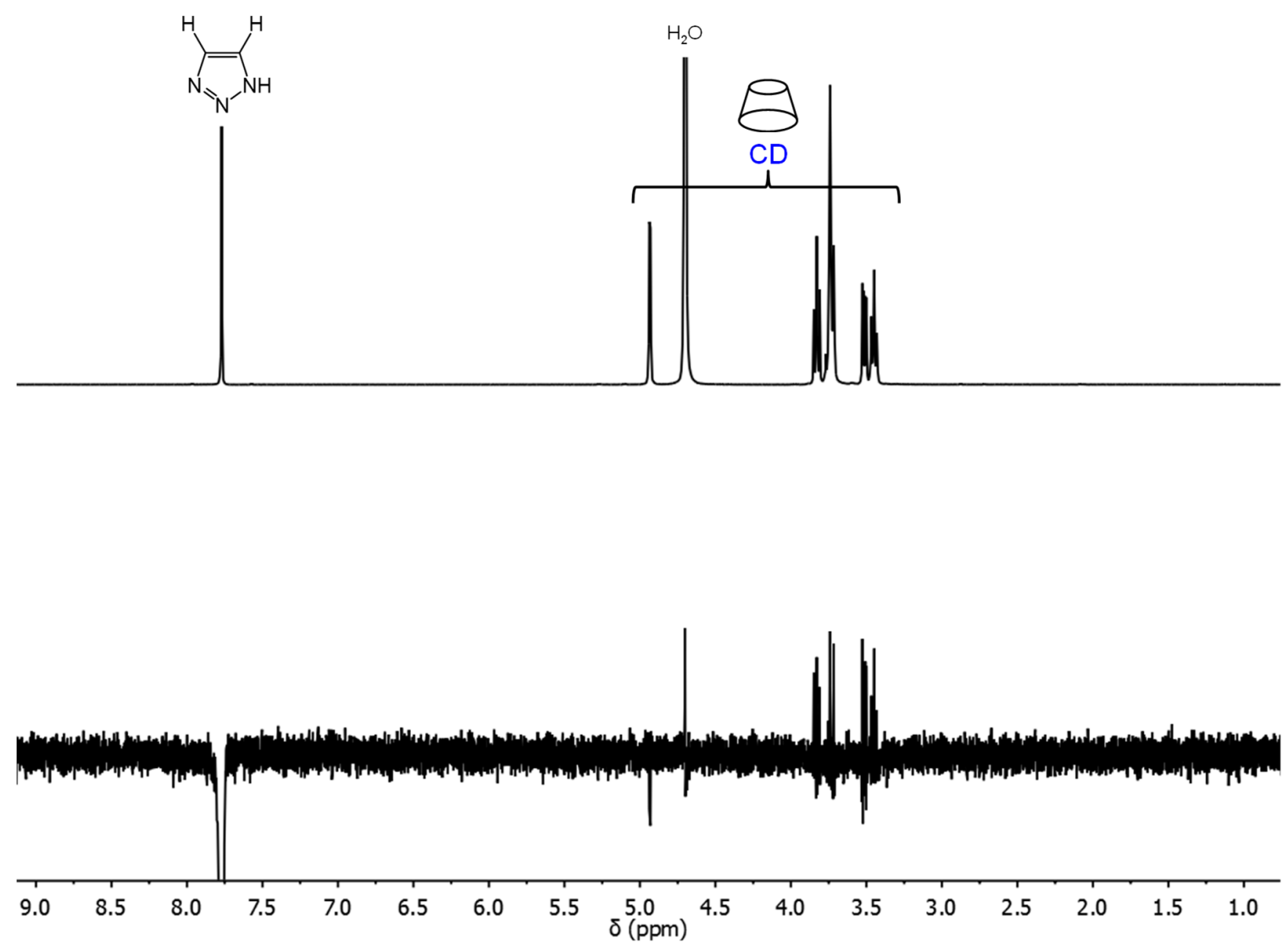

Figure S1. (upper) ${ }^{1} \mathrm{H}$ NMR spectrum (400 MHz, $\mathrm{D}_{2} \mathrm{O}$ ) and (lower) 1D ROESY NMR spectrum $\left(500 \mathrm{MHz}, \mathrm{D}_{2} \mathrm{O}\right)$ of the physical mixture of $10 \mathrm{mM} \beta-\mathrm{CD}$ and $10 \mathrm{mM}$ 1,2,3-triazole. The peak of triazole protons $(-\mathrm{CH}=\mathrm{CH}-)$ at $7.77 \mathrm{ppm}$ was set as reference. The positive peaks of CD protons were observed around $3.43-3.85 \mathrm{ppm}$, indicating the proximity of $1,2,3$-triazole to $\beta$-CD. 


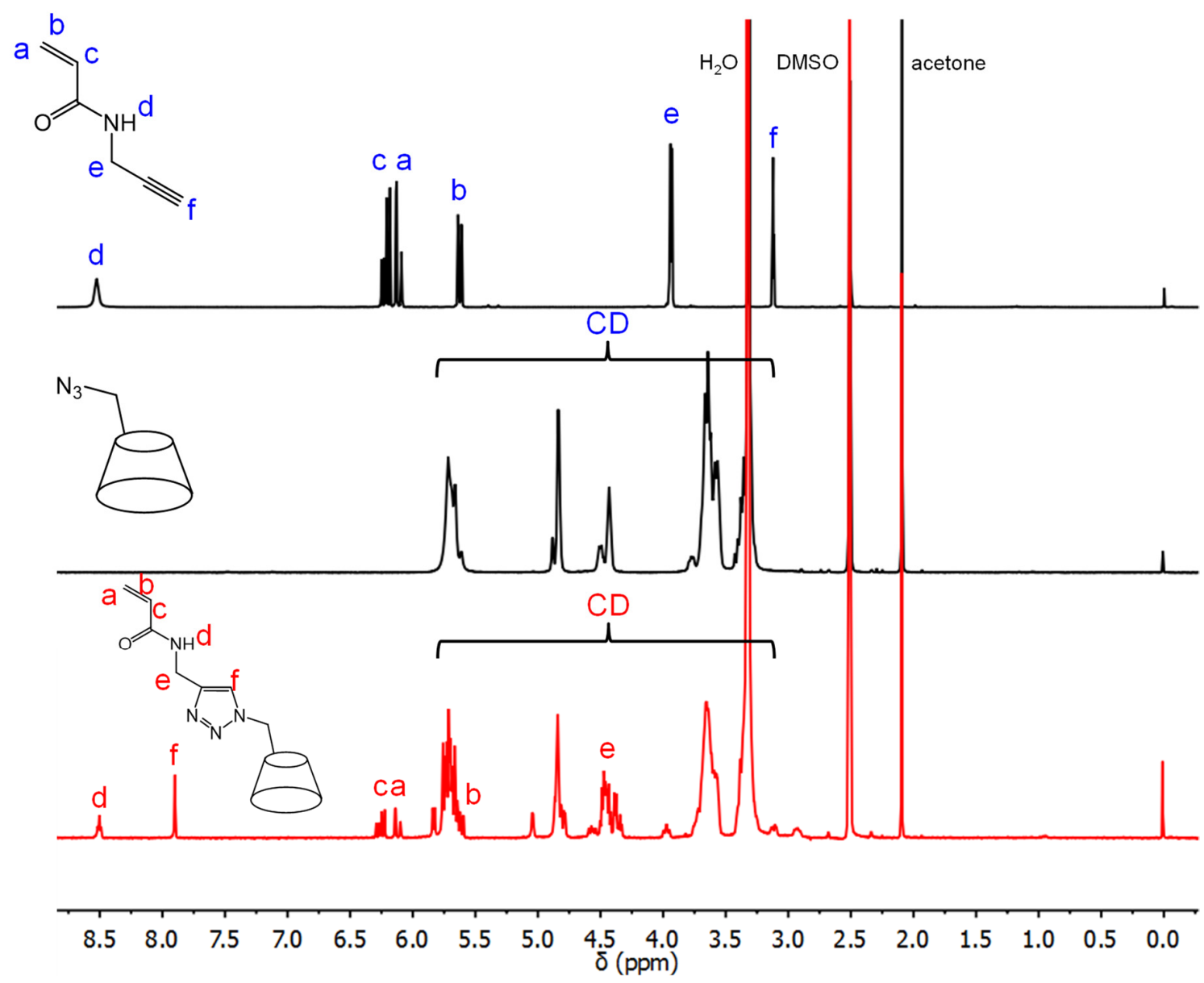

Figure S2. ${ }^{1} \mathrm{H}$ NMR spectra of (upper) $N$-propargylacrylamide, (middle) azidated $\mathrm{CD}$, and (lower) CD monomer bearing triazole moiety 2 (400 MHz, DMSO-d6). 


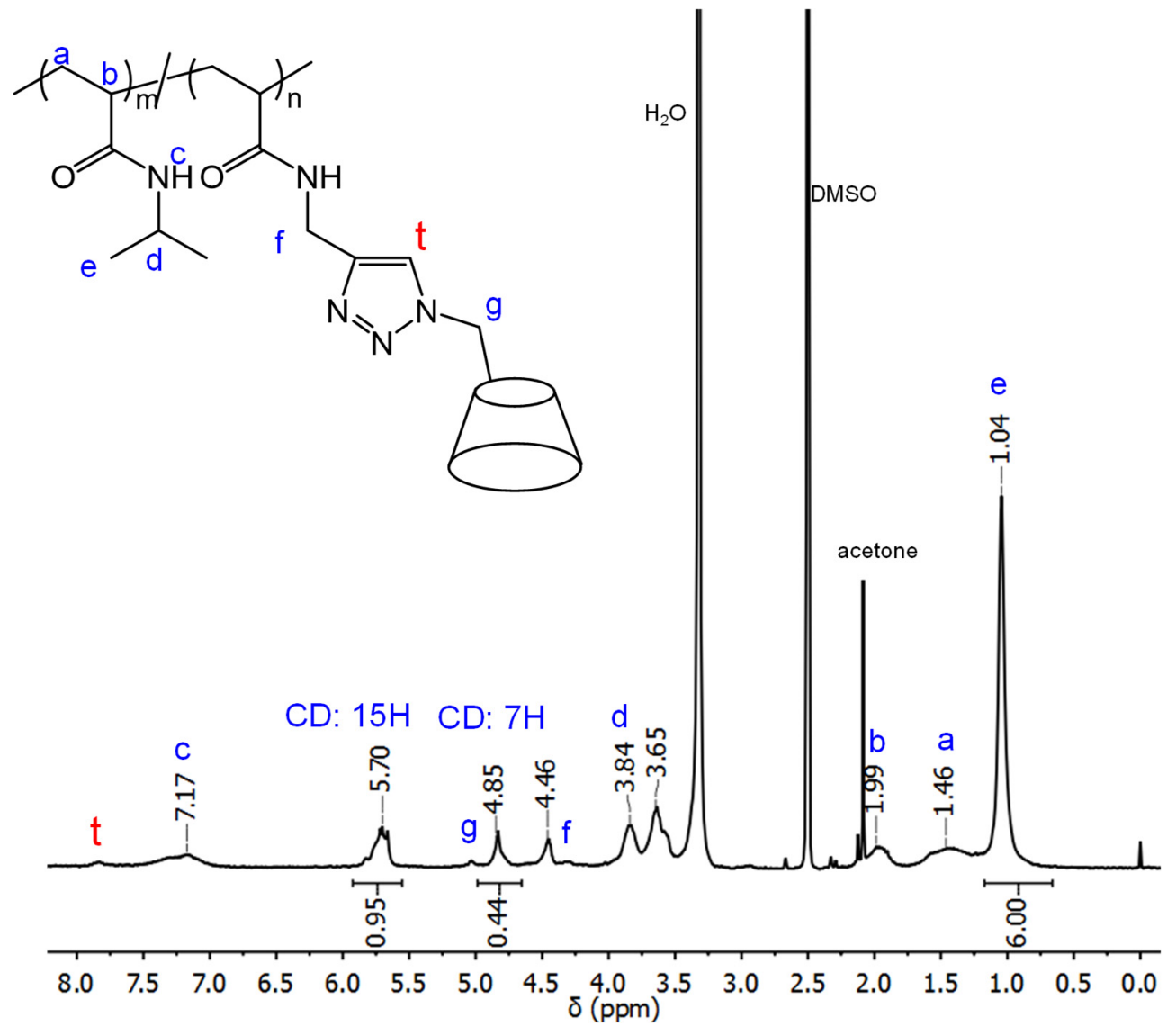

Figure S3. ${ }^{1} \mathrm{H}$ NMR spectrum of poly(NIPAM-co-triaz-CD) 3a (500 MHz, DMSO-d6). 

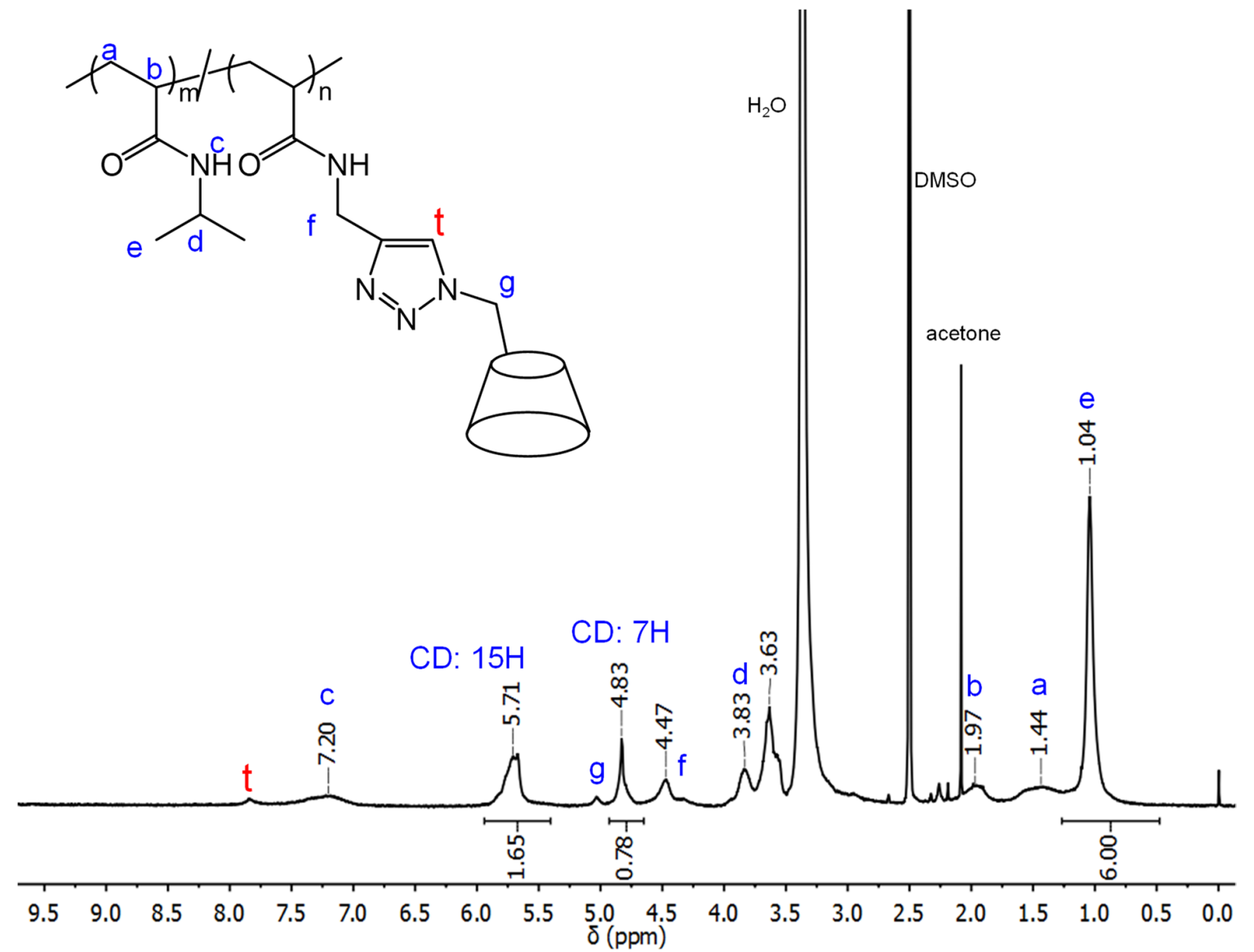

Figure S4. ${ }^{1} \mathrm{H}$ NMR spectrum of poly(NIPAM-co-triaz-CD) $\mathbf{3 b}\left(500 \mathrm{MHz}, \mathrm{DMSO}-\mathrm{d}_{6}\right)$. 


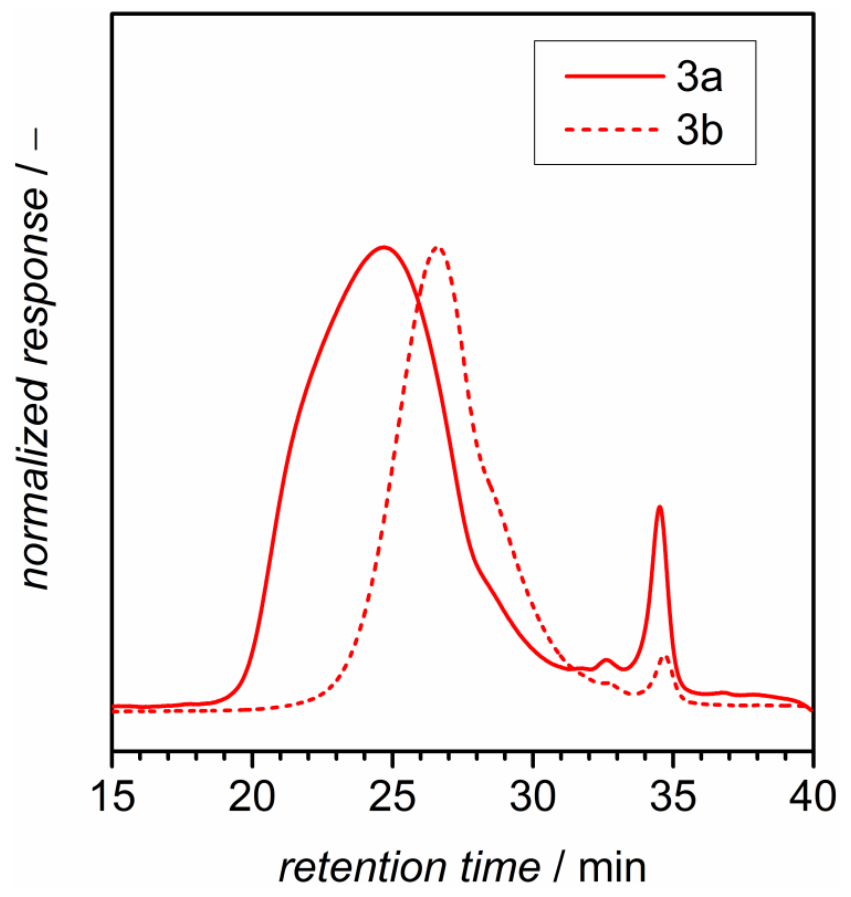

Figure S5. GPC traces of poly(NIPAM-co-triaz-CD) 3a $\left(M_{\mathrm{n}}=1.4 \times 10^{5} \mathrm{~g} \mathrm{~mol}^{-1}, M_{\mathrm{w}} / M_{\mathrm{n}}=\right.$ 2.4) and $\mathbf{3 b}\left(M_{\mathrm{n}}=2.2 \times 10^{4} \mathrm{~g} \mathrm{~mol}^{-1}, M_{\mathrm{w}} / M_{\mathrm{n}}=3.8\right)$ in DMF at $40{ }^{\circ} \mathrm{C}$. 


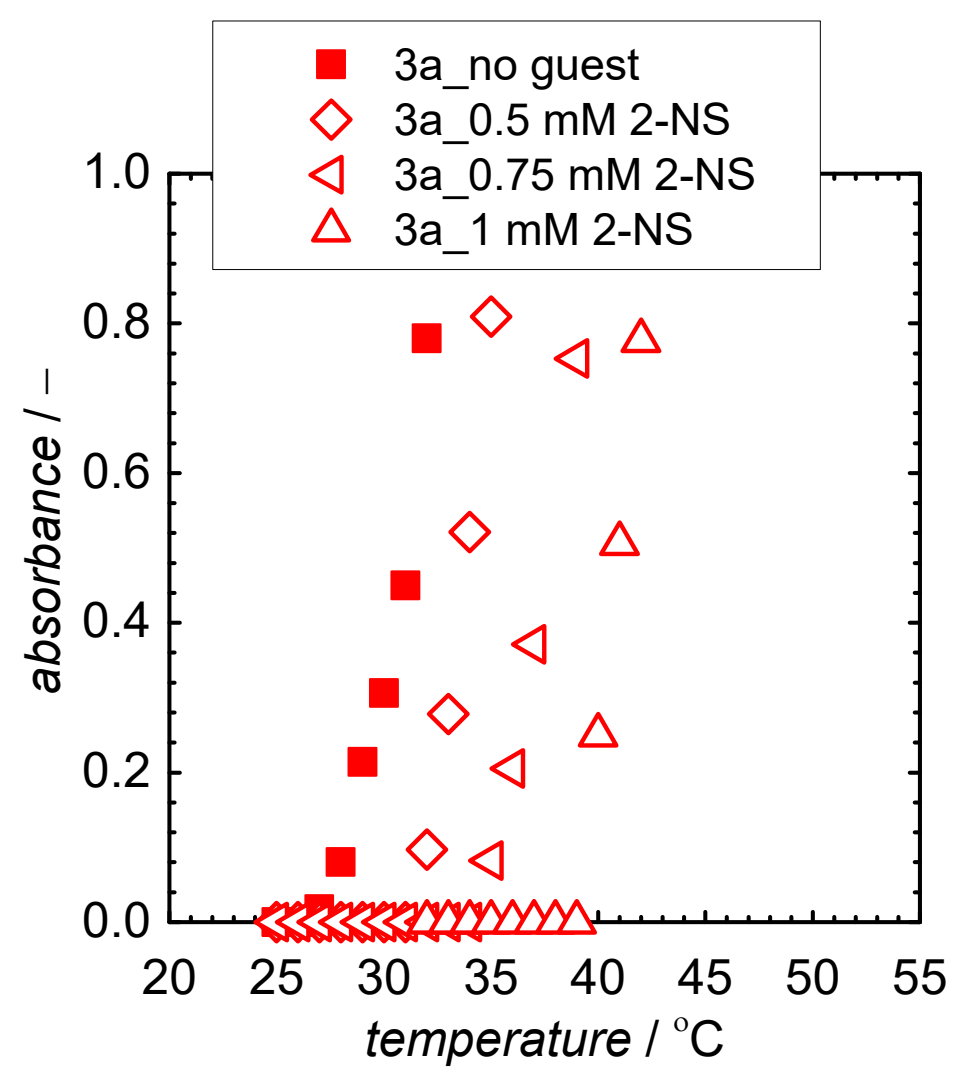

Figure S6. Phase transition behaviors of 3a. The absorbance at $650 \mathrm{~nm}$ was collected using $0.4 \mathrm{wt} \%$ aqueous polymer solutions with $0,0.5,0.75$, and $1 \mathrm{mM} 2-\mathrm{NS}$. 
(A)

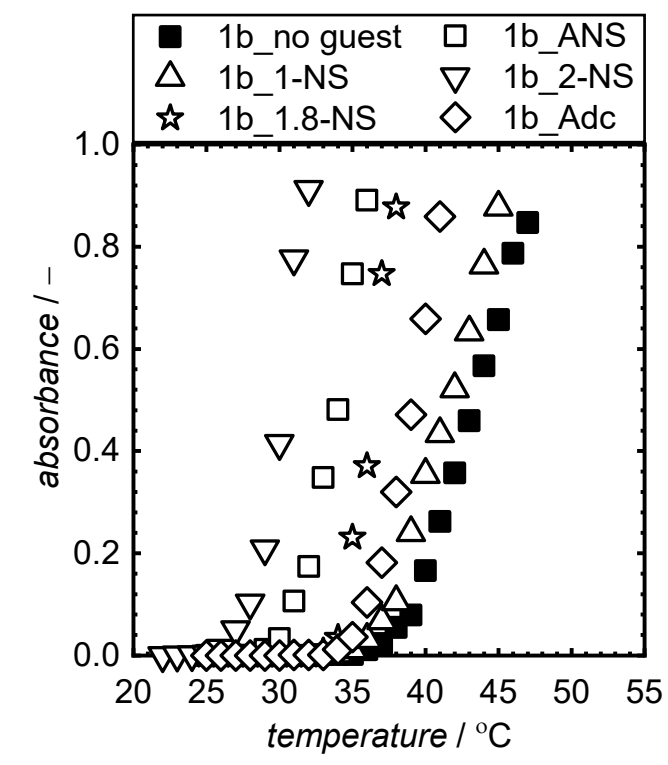

(B)

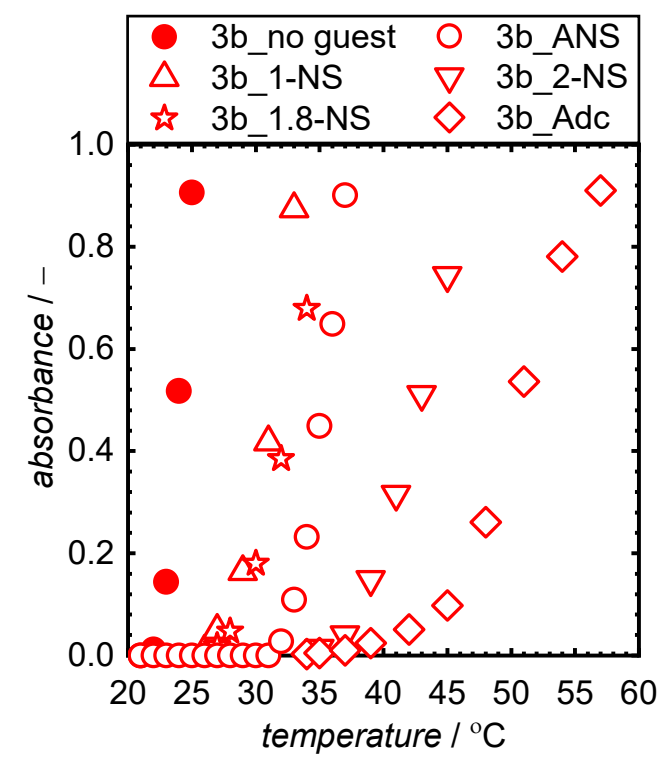

Figure S7. Phase transition behaviors of (A) poly(NIPAM-co-eda-CD) $\mathbf{1 b}$ and (B) poly(NIPAM-co-triaz-CD) 3b containing several types of free guest molecules. The absorbance at $650 \mathrm{~nm}$ was collected using $0.4 \mathrm{wt} \%$ aqueous polymer solutions with and without $1 \mathrm{mM}$ guest molecules: 1-naphatalenesulfonate (1-NS), 1-naphthol-8-sulfonate (1.8-NS), 8-Anilino-1-naphthalenesulfonate (ANS), 2-naphatalenesulfonate (2-NS), and 1-adamantanecarboxylate (Adc). 


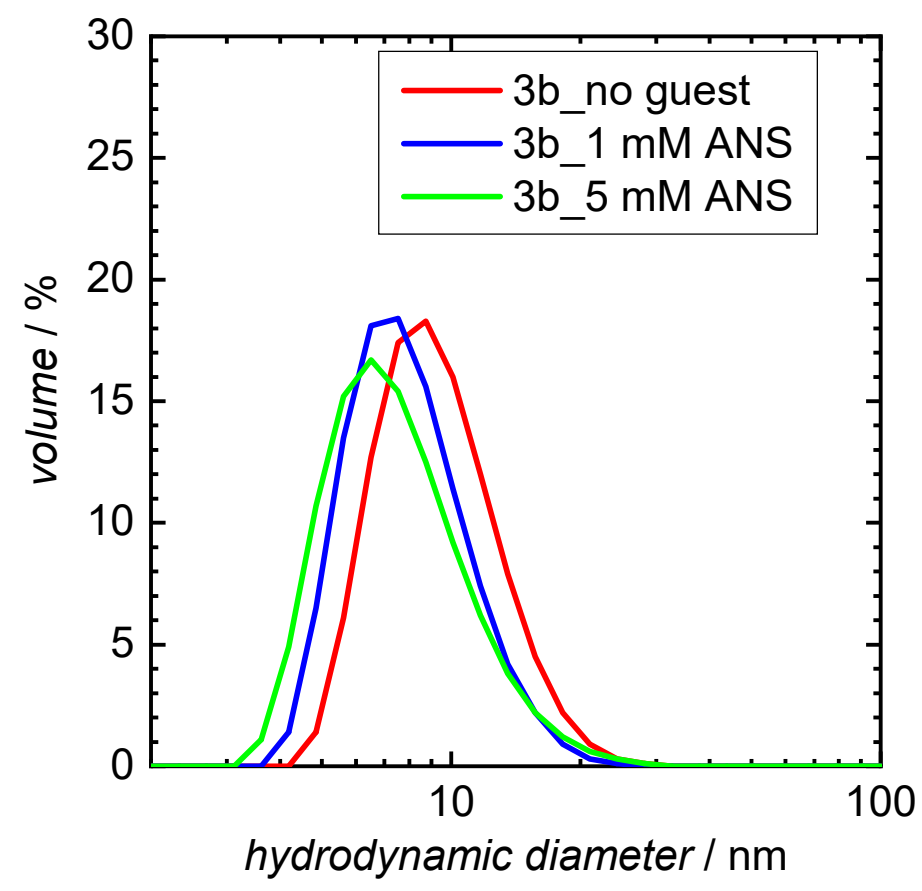

Figure S8. DLS hydrodynamic size distributions of poly(NIPAM-co-triaz-CD) 3b. The DLS measurements were performed at $20{ }^{\circ} \mathrm{C}$ using $0.4 \mathrm{wt} \%$ aqueous polymer solutions with different ANS concentrations. 


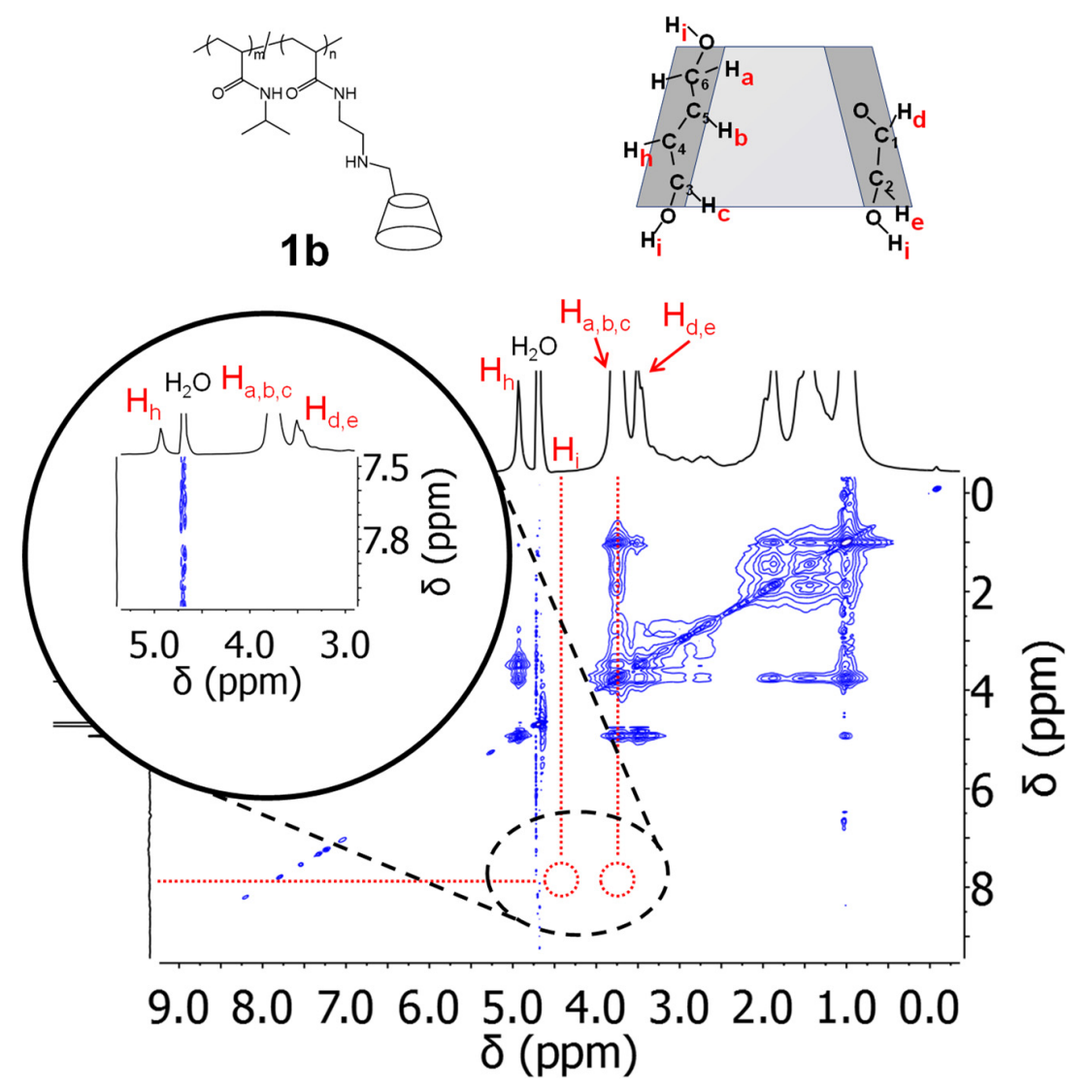

Figure S9. 2D NOESY NMR spectrum of poly(NIPAM-co-eda-CD) $\mathbf{1 b}$ in $\mathrm{D}_{2} \mathrm{O}$ at $20{ }^{\circ} \mathrm{C}$.

The chemical structure of $\mathbf{1 b}$ and the positions of inner protons of CD are also depicted on the left side of the figure. The zoomed 2D spectrum does not show any cross-correlation peaks. 
(A)

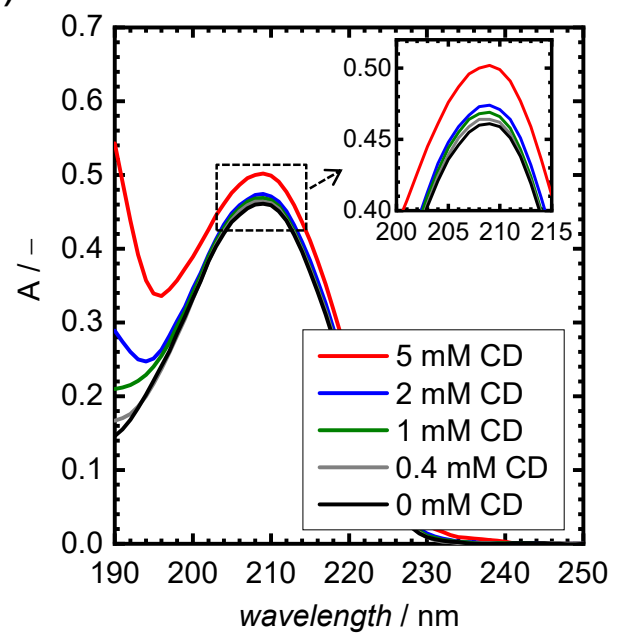

(B)

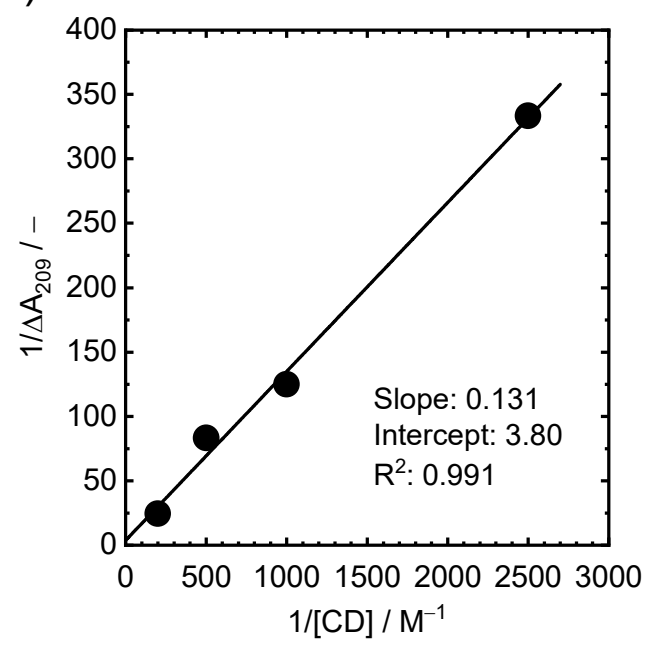

Figure S10. UV-vis spectrophotometry data obtained from $\beta$-CD and 1,2,3-triazole. (A)

UV-vis spectra of solutions containing $50 \mu \mathrm{M} \mathrm{1,2,3-triazole} \mathrm{and} \mathrm{different} \mathrm{concentrations} \mathrm{of}$

$\beta$-CD at $25^{\circ} \mathrm{C}$. (B) The Benesi-Hildebrand $\operatorname{plot}^{1}$ of data in (A) assuming the formation of

1:1 complex. 


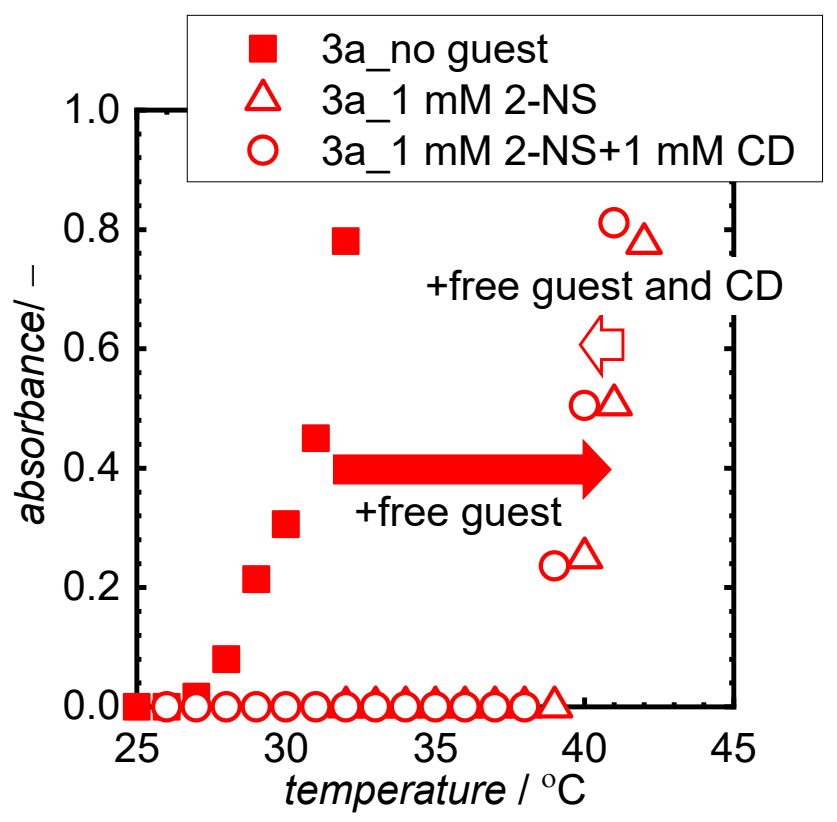

Figure S11. Phase transition behaviors of 3a. The absorbance at $650 \mathrm{~nm}$ was collected using $0.4 \mathrm{wt} \%$ aqueous polymer solutions with 3a, 3a containing $1 \mathrm{mM} 2-\mathrm{NS}$, and 3a containing $1 \mathrm{mM}$ 2-NS and $1 \mathrm{mM} \mathrm{CD}$. 
(A)

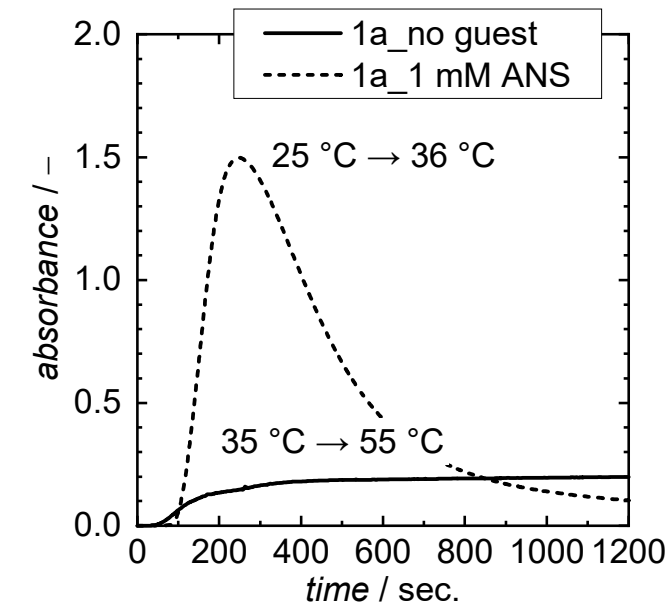

(B)

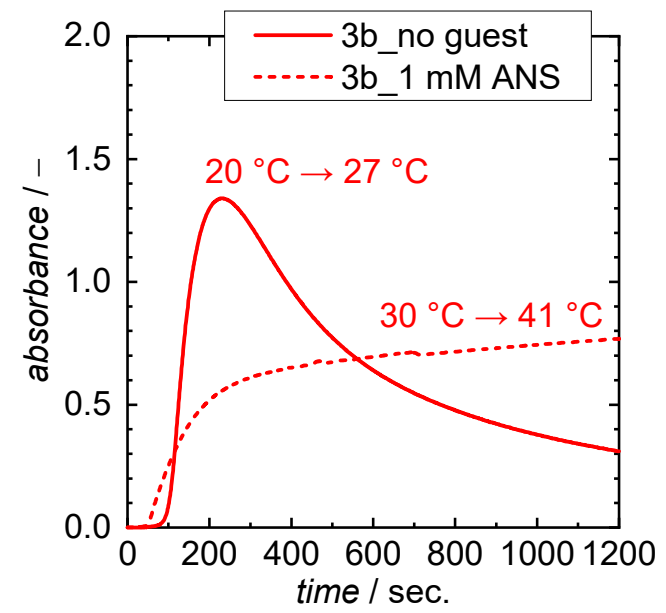

Figure S12. Time course of absorbance of (A) poly(NIPAM-co-eda-CD) 1a and (B) poly(NIPAM-co-triaz-CD) 3b in response to temperature shooting. The absorbance at 650 $\mathrm{nm}$ was collected using $0.4 \mathrm{wt} \%$ aqueous polymer solutions with and without $1 \mathrm{mM}$ ANS. 


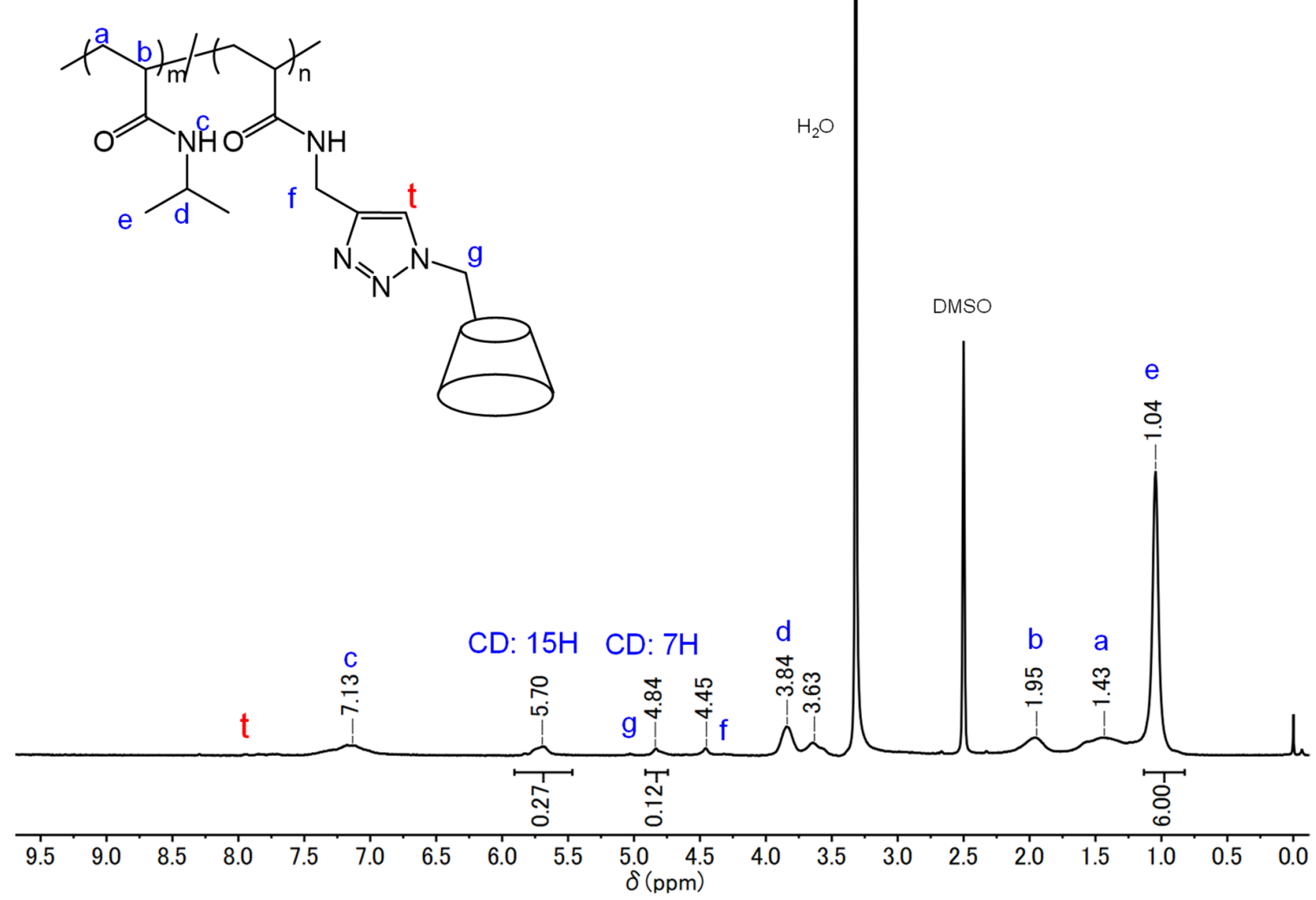

Figure S13. ${ }^{1} \mathrm{H}$ NMR spectrum of poly(NIPAM-co-triaz-CD) containing $1.8 \mathrm{~mol} \% \mathrm{CD}$ $\left(500 \mathrm{MHz}, \mathrm{DMSO}-\mathrm{d}_{6}\right) . M_{\mathrm{n}}$ is $1.5 \times 10^{5}$, and $M_{\mathrm{w}} / M_{\mathrm{n}}$ is $3.8\left(\mathrm{GPC}\right.$ in DMF at $\left.40{ }^{\circ} \mathrm{C}\right)$. 


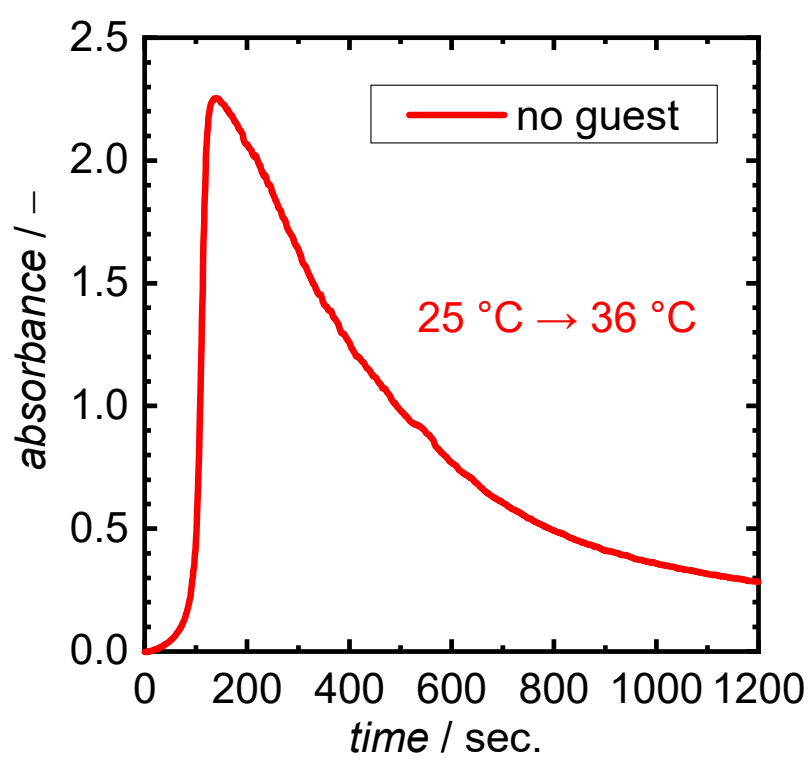

Figure S14. Time course of absorbance of poly(NIPAM-co-triaz-CD) containing $1.8 \mathrm{~mol} \%$ CD. The absorbance was obtained in the absence of free guest molecules. The starting and ending temperatures of each sample were 25 and $36{ }^{\circ} \mathrm{C}$, respectively. 


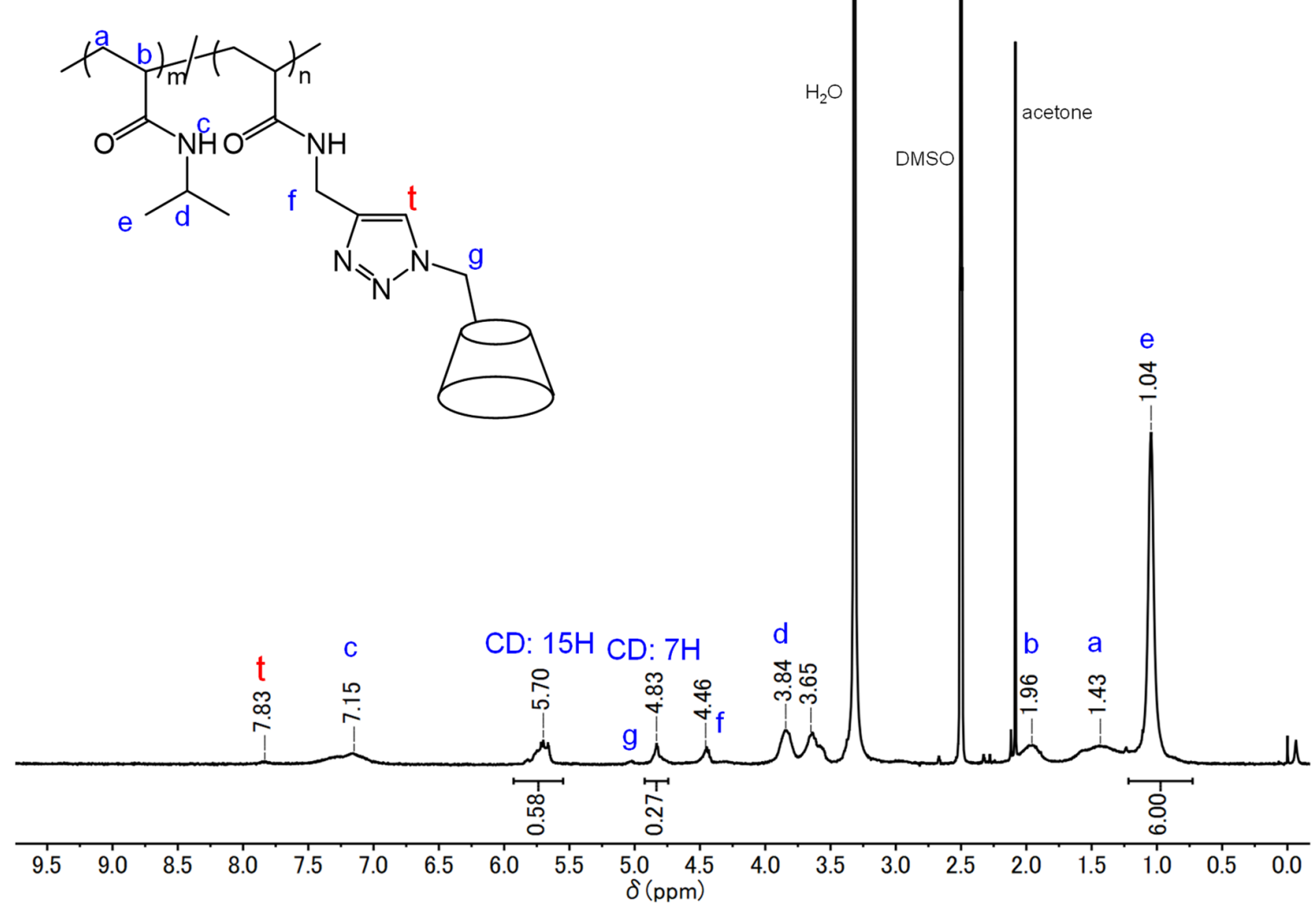

Figure S15. ${ }^{1} \mathrm{H}$ NMR spectrum of poly(NIPAM-co-triaz-CD) containing $3.9 \mathrm{~mol} \% \mathrm{CD}$ $\left(500 \mathrm{MHz}, \mathrm{DMSO}-\mathrm{d}_{6}\right) \cdot M_{\mathrm{n}}$ is $1.2 \times 10^{5}$, and $M_{\mathrm{w}} / M_{\mathrm{n}}$ is $3.4\left(\mathrm{GPC}\right.$ in DMF at $\left.40{ }^{\circ} \mathrm{C}\right)$. 


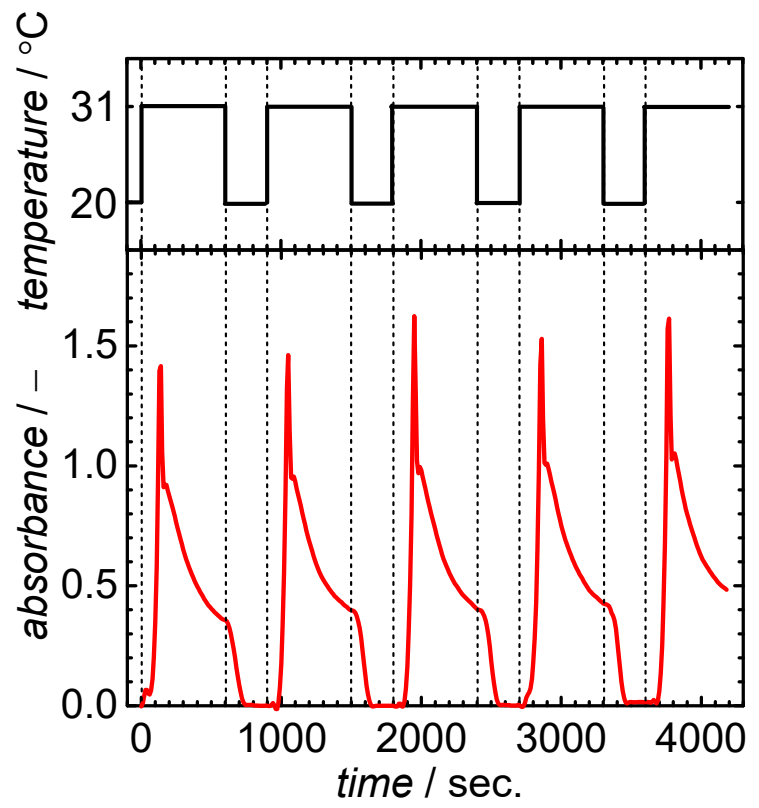

Figure S16. Examination of repeated autonomous shrinking/swelling cycles using poly(NIPAM-co-triaz-CD) bearing $3.9 \mathrm{~mol} \%$ triazole-CD units. The absorbance at $650 \mathrm{~nm}$ in response to repeated temperature shooting between $20{ }^{\circ} \mathrm{C}$ and $31{ }^{\circ} \mathrm{C}$ was collected using $0.4 \mathrm{wt} \%$ aqueous polymer solutions without guest molecules. 


\section{Determination of the Complexation Constant}

We assumed that $\mathrm{CD}$ and triazole form a 1:1 complex. The absorbance of sample solution with and without $\mathrm{CD}$ can be expressed using the following equations:

$$
\begin{aligned}
A & =\varepsilon_{\text {complex }} l[\text { complex }]+\varepsilon_{\text {triazole }} l[\text { triazole }] \\
A_{o} & =\varepsilon_{\text {triazole }} l[\text { triazole }]_{o}
\end{aligned}
$$

[complex]: concentration of CD-triazole complex

[triazole]: concentration of triazole

[triazole $]_{\mathrm{o}}$ : concentration of triazole without $\mathrm{CD}$

1: light path length $(=1 \mathrm{~cm})$

$\varepsilon_{\text {complex}}:$ extinction coefficient of complex

Etriazole: extinction coefficient of triazole

The variation of absorbance by the addition of $\mathrm{CD}$ can be expressed using following equation:

$$
\begin{aligned}
\Delta A & =A-A_{o}=\varepsilon_{\text {complex }}[\text { complex }]+\varepsilon_{\text {triazole }}[\text { triazole }]-\varepsilon_{\text {triazole }}[\text { triazole }]_{o} \\
& =\varepsilon_{\text {complex }}[\text { complex }]+\varepsilon_{\text {triazole }}\left([\text { triazole }]-[\text { triazole }]_{o}\right) \\
& =\varepsilon_{\text {complex }}[\text { complex }]+\varepsilon_{\text {triazole }}[\text { complex }]=\left(\varepsilon_{\text {complex }}-\varepsilon_{\text {triazole }}\right)[\text { complex }]
\end{aligned}
$$




$$
=\Delta \varepsilon[\text { complex }]
$$

Complexation constant $K$ is expressed using [complex] as follows:

$$
[\text { complex }]=\frac{[\text { triazole }]_{o} K[C D]}{1+K[C D]}
$$

$\Delta \mathrm{A}$ can be subsequently expressed as follows:

$$
\frac{\Delta A}{\Delta \varepsilon}=\frac{[\text { triazole }]_{o} K[C D]}{(1+K[C D])}
$$

When $[\text { triazole }]_{\mathrm{o}}<<[\mathrm{CD}]_{\mathrm{o}},[\mathrm{CD}]_{\mathrm{o}}=[\mathrm{CD}]$. Therefore, $\Delta \mathrm{A}$ can be expressed as follows:

$$
\begin{gathered}
\Delta A=\frac{[\text { triazole }]_{o} K[C D]_{o} \Delta \varepsilon}{\left(1+K[C D]_{o}\right)} \\
\frac{1}{\Delta A}=\frac{1}{\Delta \varepsilon[\text { triazole }]_{o} K} \frac{1}{[C D]_{o}}+\frac{1}{\Delta \varepsilon[\text { triazole }]_{0}}
\end{gathered}
$$

If $1 / \Delta \mathrm{A}$ is plotted against $1 /[\mathrm{CD}]_{\mathrm{o}}$ (Benesi-Hildebrand plot $^{1}$ ), its slope and intercept can provide $K$.

According to the series of UV-vis measurements, the following values were obtained.

Slope: 0.131

Intercept: 3.80

$K: 29$

$\log K: 1.5$ 


\section{Quantification of CD-Triazole Complex}

We assumed that $\mathrm{CD}$ and triazole form a 1:1 complex. The concentration of $\mathrm{CD}$-triazole complex can be described using complexation constant $K$ as follows:

$$
\begin{aligned}
K=\frac{[\text { complex }]}{[C D][\text { triazole }]} & =\frac{[\text { complex }]}{\left([C D]_{\mathrm{o}}-[\text { complex }]\right)\left([\text { triazole }]_{\mathrm{o}}-[\text { complex }]\right)} \\
& =\frac{[\text { complex }]}{\left([C D]_{\mathrm{o}}-[\text { complex }]\right)^{2}}
\end{aligned}
$$

[CD]: concentration of CD

[triazole]: concentration of triazole

[complex]: concentration of CD-triazole complex

$[C D]_{\mathrm{o}}$ : initial $[\mathrm{CD}]=[\text { triazole }]_{\mathrm{o}}$ : initial [triazole $]$

(1) $3 \mathbf{a}(6.0 \mathrm{~mol} \% \mathrm{CD})$

In a $0.4 \mathrm{wt} \%$ polymer solution, $[\mathrm{CD}]_{\mathrm{o}}$ is $1.3 \times 10^{-3} \mathrm{M}$.

$$
29=\frac{[\text { complex }]}{(0.0013-[\text { complex }])^{2}}
$$

[complex] is $4.7 \times 10^{-5} \mathrm{M}$.

$[$ complex $] /[\mathrm{CD}]_{\mathrm{o}} \times 100=3.5 \%$ 
(2) $\mathbf{3 b}(10 \mathrm{~mol} \% \mathrm{CD})$

In a $0.4 \mathrm{wt} \%$ polymer solution, $[\mathrm{CD}]_{\mathrm{o}}$ is $1.8 \times 10^{-3} \mathrm{M}$.

$$
29=\frac{[\text { complex }]}{(0.0018-[\text { complex }])^{2}}
$$

[complex] is $8.1 \times 10^{-5} \mathrm{M}$.

$[$ complex $] /[\mathrm{CD}]_{\mathrm{o}} \times 100=4.6 \%$ 


\section{Reference}

(1) Benesi, H. A.; Hildebrand, J. H. A Spectrophotometric Investigation of the Interaction of Iodine with Aromatic Hydrocarbons. J. Am. Chem. Soc. 1949, 71, 27032707. 